\title{
Comportement clinique et immunologique, lors de contamination bovipestique, de bovins vaccinés depuis plusieurs années contre la peste bovine avec des vaccins de cultures cellulaires
}

\author{
par A. PROVOST, Y. MAURICE ef C. BORREDON* \\ (l. E. M. V. T., Laborataire de Recherches Vétérinaires de Farcha, \\ Fort-Lamy, Tchad)
}

\begin{abstract}
RÉSUMÉ
Dans les conditions de l'expérience (zébus de 2 ans, vaccinés contre la peste bavine à dose recommandée dans la pratique avec deux vaccins de cultures cellulaires différents, puis entretenus à l'abri de toute contaminatıon pestique), on constate que $33 \mathrm{p}$. 100 des bovins vaccinés ont perdu leurs anticorps sériques antipestiques post-vaccinaux au bout de 2 ans.

De tels bovins vaccinés, mais à sérologie pestique positive, soumis 25 mois après la vaccınation ì une épreuve virulente par contact, ne font pas de peste elinique mais peuvent véhıculer le virus dans leur mucus nasal et contamıner un bovin réceptif placé à leur contact. A l'épreuve virulente faite la $3^{\mathrm{e}}$ année, 7 bovins sur 17 contractent la peste, 3 ont une montée de leurs antıcorps.

On est conduit à penser que lorsque les bovins vaccinés ne sont pas soumis à des recontaminations, l'immunité anfipestique engendrée par les vaceins de cultures cellularres ne dure pas toute la vie chez certains d'entre eux et, par ailleurs, que des bovins immuns peuvent être des véhicules méconnus du contage pestique.
\end{abstract}

«C'est en cherchant le vraı que I'on découvre l'utile.» Adolphe WURTZ.

\section{INTRODUCTION}

C'est un lieu commun que d'affirmer la pérennité de l'ımmunité spontanément acquise dans la peste bovine naturelle : les témoignages classiques le confirment.

$\mathrm{Si}$ la durée de l'efficacité de la vaccination

\footnotetext{
* Aide technique de $M^{m e}$ G. DUFAU et de M. Z. GNAL-
} DAM. antipestique avec les vaccins antipestiques inactivés, quel qu'en soit d'aılleurs le mode de préparatıon, était plus ou moins durable comme I'a montré une longue suite de travaux, il a fallu attendre ces dernières années pour avoir l'assurance que, fout comme la maladie naturelle, la vaccination avec le virus caprınisé condusait à une immunité valable pour la vie économique du bovin vacciné (6). II n'en est pas de même du vaccin lapinısé ni du vaccin 
d'ovoculture; on donne pour le premier les chiffres de 8 à 15 mois de protection (5), pour le second de 1 an à 20 mois selon la souche utilisée $(6,19,22)$.

En ce qui concerne le vaccin de cultures cellulaires et plus spécialement celui préparé avec la souche RPOK-BK de PLOWRIGHT et FERRIS (13) utilisée quasi exclusivement en Afrique, les premiers résultats indiqualent qu'une dose de $10^{4,1}$ DCP $_{50}$ de virus de culture du $40 \mathrm{e}$ passage en cellules rénales de veau $\left({ }^{*}\right)$ inoculé au bétail amélioré du Kénya le protégeait pendant au moins 4 ans (10). L'auteur reconnaissait toutefois que « de plus petites doses de virus vaccinal ou son utilisation chez un type de bétall plus résistant pouvait, bien sûr, apporter des changements à cette affirmation $»$. En dehors des deux paramètres cités, dose vaccinale et type de bétail, on pouvait aussi se demander si le degré d'atténuation de la souche, corallaire de l'augmentation de ses passages en culture, n'avait pas également une influence ; pour n'y plus revenir, qu'il soit dit maıntenant que le vaccin utılisé en Afrique centrale (Tchad, Cameroun, R. C. A.) a été produit avec les $35^{\mathrm{e}}$ et $36^{\mathrm{e}}$ passages en cellules rénales secondaires de veau, donc avec un virus juste à la limite de son atténuation et qui parfols provoque une petite montée thermique chez quelques vequx, montée de peu d'amplıtude et non accompagnée d'autres symptômes.

Ceci dit, II n'était pas certain que chez le zébu rustique de l'Afrique centrale, tout se passât comme chez le bétall amélioré du Kénya qui contient une forte proportion de sang des races européennes. En effet, les mécomptes enregistrés dans l'emplor du vaccın avıanisé souche BA chez ce zébu rustique, contrastant avec ce qui avait été vu ailleurs oư il déterminait à la fois réactions post-vaccinales légères et immunıté valable (19, 22), devaient inciter à la prudence et interdire d'affirmer que ce qui étalt vrai au Kénya devalt l'être aussi au Tchad. L'expérience s'imposait ; elle fait l'objet de ces lignes.

Lorsqu'elle fut mise en place, une autre question se posait. Des résultats expérimentaux acquis à Dakar et à Farcha (1) montraient que

(*) Il s'agit d'une dose très importante, correspondant à plus de 10.000 doses minima vaccinales et qui est hors de proportions avec ce que l'on inocule dans la pratique. des bovins vaccinés contre la peste, soit avec un vaccin inactivé, soit avec un vaccin de cultures celiulaires, étaient capables d'héberger le virus pestique de contamination lors d'une épreuve virulente, sans pour cela extérioriser les signes cliniques de la peste bovine. Une publication récente de BOURDIN (4) confirme ces résultats prélıminaires en indiquant que chez des bovins vacanés avec un vaccin inactivé et soumis trois semaines plus tard d̀ un aérosol infectıeux, on peut retrouver le virus bovipestıque dans le système lymphatique jusqu'au $19 \mathrm{e}$ jour après le contact alors que sont présents des anticorps sériques neutralisants.

De tels animaux, apparemment immuns, peuvent-ils excréter le virus de contamination et être ainsi des colporteurs méconnus du contage? Un doute naissant, il tombe sous le sens que seule une expérience pouvait le lever. C'est ainsi que décision fut prise de coupler cette dernière avec celle sur la durée de l'ımmunité dont la genèse a été exposée ci-dessus.

\section{MATÉRIEL ET MÉTHODES}

1. Principes expérimentaux. Disposer d'un fond de bovins vaccinés contre la peste bovine dans des conditions connues mais identiques à celles que rencontre le cheptel dans les campagnes de vacanation, les entretenir pendant toute la durée de l'expérience à l'abri de toute contamination bovipestıque éventuelle, suivre la cinétique de leurs anticorps sériques, en soumettre à des temps variables une fraction aliquote à une contamination pestique sımulant la contamination naturelle, juger de l'immunité tant clinique que sérologique des bovins ainsi éprouvés et de leur possibilité d'excrétion de virus pathogène pouvant infecter des bovins réceptifs mıs à leur contact.

2. Voccins uthlisés. Deux vaccins de cultures cellulaires produits par nos solns sont entrés en expérience; tous deux étaient lyophilisés.

L'un a été préparé avec la souche RPOK-BK de PLOWRIGHT et FERRIS (13) selon le protocole de production par ailleurs décrit pour le virus de cultures cellulaires (16) ; ils constituait le lot no 7 du vaccin Pestosec du Laboratoire de Farcha utilisé dans la campagne PC15. Le titrage lui assignait une richesse de $10^{2,9} \mathrm{DCP}_{50}$ par dose 
vaccinale, c'est-à-dire un titre déjà supérieur aux normes admises (2).

L'autre vaccin a été préparé dans des conditions similaires avec la souche américaine de Plum Island (7) qui, si elle possède apparemment les mêmes qualités d'atténuation que la précédente, a de surcroît l'avantage d'être clonée et donc, a priori, d'être génétiquement stable $\left(^{*}\right)$. Un lot de vaccin a été produit pour les besoins stricts de la présente expérience et $\pi^{\prime} \alpha$ pas été diffusé par ailleurs. Il contenalt $10^{2,7}$ $\mathrm{DCP}_{\text {ต0 }}$ de virus par dose vaccinale.

De leur production à leur utilisation, les deux vaccins ont été maintenus sous froid, solt au congélateur à $-20^{\circ} \mathrm{C}$ soit sous glace fondante au cours du transport. La reconstitution lors de la séance vaccinale a été falte avec de l'eau distıllée glacée, le produit reconstitué maintenu en glace fondante et inoculé dans la demi-heure suivante.

3. Bovins d'expérience. o) Groupe de bovins réceptifs. Etant au nombre de 5 au total, 4 ont été achetés selon les besoins et un a été entretenu pendant 3 ans avec le groupe vacciné. Tous ces animaux, y compris ceux des groupes suivants, ont été obtenus dans la région de Bovar en R. C. A., état indemne de peste bovine depuis plusieurs décennies et où, de ce fait, aucune vaccination antipestique n'est pratiquée; une prise de sang de contrôle permeł de s'assurer qu'ils n'hébergent aucun anticorps antipestique avant la vaccination. Ils sont venus au Tchad en bétaillère close et placés en étables d'isolement.

b) Groupe de bovins contaminants. Quatre animaux de même origine ont été amenés à Fort-Lamy en bétaillère et placés en étables d'isolement. Par groupe de deux, selon le protocole ci-après détaillé (nos 3505 et $3528 ; 5002$ et 5005), ils reçaivent un aérosol de virus bovipestique souche DK selon le procédé désormais classique à Farcha (17) puis sont placés en contact avec des bovins du groupe suivant.

c) Groupe vacciné. Cinquante et un zébus de race Bororo brun acajou, âgés d'environ deux

(*) Les Docteurs J. J. CALLIS et C. J. De BOER (U.S. Department of Agriculture, Plum Island Anımal Disease Laboratory, Greenport, Long Island, N. Y., USA) ont très aimablement mis cette souche à la disposition du Laboratoire de Farcha; qu'ils en soient ICi remerciés. ans, sont entrés dans l'expérience de vaceınation.

Celle-ci est pratıquée de la manière suivante (*) : 24 anımaux (nos 3003 à 3027) reçoivent par voie sous-cutanée rétroscapulaire une dose de vaccin souche RPOK-BK ; 25 autres ( $n^{\text {os }} 3029$ à 3053) sont inoculés avec une dose de la souche de Plum Island; deux, enfin, non vaccinés (nos 3056 et 3057), sont laıssés en contact avec le groupe vacciné.

Pendant toute la durée de l'expérience, ces bovins sont parqués à Bouar au pâturage, dans un milieu libre de toute contamınation pestique. Le point est d'importance ; on a ainsi les conditions d'une de ces «zones protégées» dont la création est envisagée et chaudement recommandée par l'Office International des Epizooties pour permettre le transit des bovins avant leur exportation comme bétail sur pied ou leur abattage suivi de l'exportation des carcasses réfrigérées. Les conclusions que l'on tirera de la présente expérience pourront s'appliquer à de telles zones.

Les vaccinés sont soumis à une prise de sang périodique permettant de suivre l'évolution des anticorps sériques.

Deux ans après la vaccination, on sélectionne 8 animaux (4 dans chacun des groupes : 3006 , 3008,3011 et 3026 parmı ceux ayant reçu le vaccin Pestosec : 3038, 3039, 3045 et 3050 parmi ceux ayant reçu la souche de Plum Island) ; le choix est fait au vu de la sérologie morbilleuse (présence d'antıcorps résiduels post-vaccınaux Inhibant l'hémagglutination morbilleuse), en se posant la question de savoir si un test sérologique simple d̀ mettre en œuvre pouvait constituer l'assurance d'une immunité complète, à la fois clinique et virologique, lors d'une contamination pestıque. De Bouar, ces 8 bovins sont amenés à Farcha en bétaillère close. Après un repos de quelques jours en étable d'isolement, ils sont placés en contact avec deux zébus qui sont au $4 \mathrm{e}$ jour de la manifestation clinique d'une peste bovine expérimentale ainsi qu'ıl a été dit plus haut. Ce made de contamination par contact avec des malades paraît être plus proche de la réalité que celui qui avait été réalisé dans des

(*) A notre confrère P. FINELLE qui, à Bouar, prit le soin de réaliser cetie vaccination et de surveiller ensuite les anımaux, va toute notre gratitude. 
essais précédents $(1,4)$ où les animaux vaccinés recevaient un copieux aérosol de virus bovipestique; parfait pour conférer la maladie à des bovins neufs, par exemple, on peut craindre que le procédé touche des récepteurs tissulaıres autres que ceux normalement atteints lors de transmissions naturelles du contage. Trois jours plus tard, les deux bovins contaminants sont abattus; ils sont d'ailleurs à l'agonie. On change les 8 bovins contamınés de parcours et on les fait passer sous une douche antiseptique pour qu'un éventuel virus pestique résiduel sur le sol ou le pelage (cas bien improbable au demeurant) ne vienne pas contamıner le bovin témoın réceptif à la peste ( $0^{\circ} 2980$ ) que l'on introduit alors avec eux. On examine chaque jour les anımaux (examen clınıque et relevé thermométrique). Des prélèvements de mucus nasal sont réalisés quotidiennement pendant 5 jours à partir du 10 jour après la mise en contact des 8 vaccinés avec les deux pestiques; on y recherche le virus pestique ef une activité neutralisante du mucus selon les modalités techniques commentées plus bas. Tous les bovins sauf le no 3045 sont abattus le $20^{\mathrm{e}}$ jour après le début de la mise en contact.

Trois ans après la vaccination, restaient dans la station de quarantaine de Bouar 39 bovins en expérience, dont les deux témoins non vaccinés. Dix-sept d'entre eux (dont 16 vaccinés et un non vacciné, no 3057) sont transférés en bétaillère à Fort-Lamy. Après quelques jours de repos, les 16 bovins vaccinés sont placés en contact avec deux bovins pestiques (nos 5002 ef 5005) au $2^{\mathrm{e}}$ jour de leur réaction clinique. Au bout de 48 heures de contact, ces deux derniers meurent à quelques heures d'intervalle l'un de l'autre. Après avoir répété le protocole précédent de changement de parcours et de désinfection, on introduit 24 heures plus tard 4 animaux neufs. (nos 3057, 5023, 5024, 5025) avec les 16 vaccinés. contaminés. L'examen clinıque est réalisé tous. les jours, sans relevé thermométrique. Des prélèvements de sang sont effectués les $3 \mathrm{e}$ et $11 \mathrm{e}$ jours après la mise en contact et des prélèvements de mucus nasal les 5,8 et $10^{\mathrm{e}}$ jours. Les anımaux survivant à la fin de l'expérience n'onf pas été abattus.

Le tableau no 1 résume le déroulement des. essais.

4. Techniques de laboratoire. a) Isolement de virus à partır du mucus nasal. Obtenu, après. nettoyage des naseaux à l'alcool-éther, par insertion dans la cavité nasale d'un tampon de coton cardé monté sur une tige souple en bois, le mucus nasal récolté est exprimé dans quelques millilitres de solution saline tamponnée polyantibiotique ; l'échantillon est alors congelé d̀ $-20^{\circ} \mathrm{C}$, procédé qui permet de traiter en même temps tous les prélèvements et surtout de diminuer les contaminations fongiques.

Les prélèvements seront ensuite ensemencés. après décongélation sur tapis cellulaire de cellules secondaires de rein d'embryon de veau

TABLEAIJ $\mathrm{I}^{\circ} \mathrm{I}$

Réswimé de l'expérıence : vaccınetion et épreuves virulentes.

\begin{tabular}{|c|c|c|c|c|c|c|c|c|}
\hline $\begin{array}{l}\text { Nature de } \\
\text { l'essai }\end{array}$ & Dave & \multicolumn{3}{|c|}{ Bovins vaccinés } & \multicolumn{2}{|c|}{$\begin{array}{c}\text { Bovins } \\
\text { conteminants }\end{array}$} & \multicolumn{2}{|c|}{$\begin{array}{l}\text { Bovins } \\
\text { témoins }\end{array}$} \\
\hline Vaccinetion & $15-3-65$ & \multicolumn{3}{|c|}{$\begin{array}{l}3003 \text { à } 3027 \\
3029 \text { aे } 3053\end{array}$} & & & \multicolumn{2}{|c|}{$\begin{array}{l}3056 \\
3057\end{array}$} \\
\hline Iè épreuve & $8-4-67$ & \multicolumn{3}{|c|}{$\begin{array}{l}3006 \\
3011 \\
3038 \\
3045\end{array}$} & 3505 & 3528 & \multicolumn{2}{|c|}{2980} \\
\hline ¿è épreuve & $27-4-68$ & $\begin{array}{l}3003 \\
3010 \\
3021 \\
3035 \\
3043 \\
30.48\end{array}$ & $\begin{array}{l}3005 \\
3016 \\
3022 \\
3040 \\
3051\end{array}$ & $\begin{array}{l}3007 \\
3020 \\
3042 \\
3046 \\
5026\end{array}$ & 5002 & 5005 & $\begin{array}{l}3057 \\
5024\end{array}$ & $\begin{array}{l}5023 \\
5025\end{array}$ \\
\hline
\end{tabular}

+ = Cet animal ayant perdu sa bcucle nurérotée à l'arrivée au Lacoratoire a été renuméroté et est vralserbiliblement le 3053 original. 
en tubes roulants. La lecture intervient 12 jours après l'ensemencement. L'agent cytopathogène éventuellement présent est identifié par séroneutralisation avec un immunsérum de lapin antibovipestique.

b) Techniques sérologiques. Classiques, faisant appel d̀ la séro-neutralisation (14) et à l'inhibifion de l'hémagglutination morbilleuse (3).

La présence éventuelle d'une actıvité inhibitrice du virus bovipestique dans le mucus nasal a été recherchée par séro-neutralisation en cul- tures cellulaires. Prélevé et traité ainsi qu'if vient d'être dit, le mucus en dilution dans le tampon phosphaté est inactivé pendant $30 \mathrm{mn}$ à $56^{\circ} \mathrm{C}$ pour détruire un virus pestique éventuellement présent ; il est ensuite traité comme le serait un sérum, sans être plus dilué toutefois.

\section{RÉSULTATS}

1. Cinétique des anticorps post-vaccicaux (tableau 2). Les résultats partiels ont été présentés

TABLEAU $N^{\circ}$ II

Evolution des anticorps inhibant l'hémagglutınation norbillelse (IHM) et neutralisant le virus bovipestique (SN) dens les sérurs de zébus vaccinés cortre la peste.

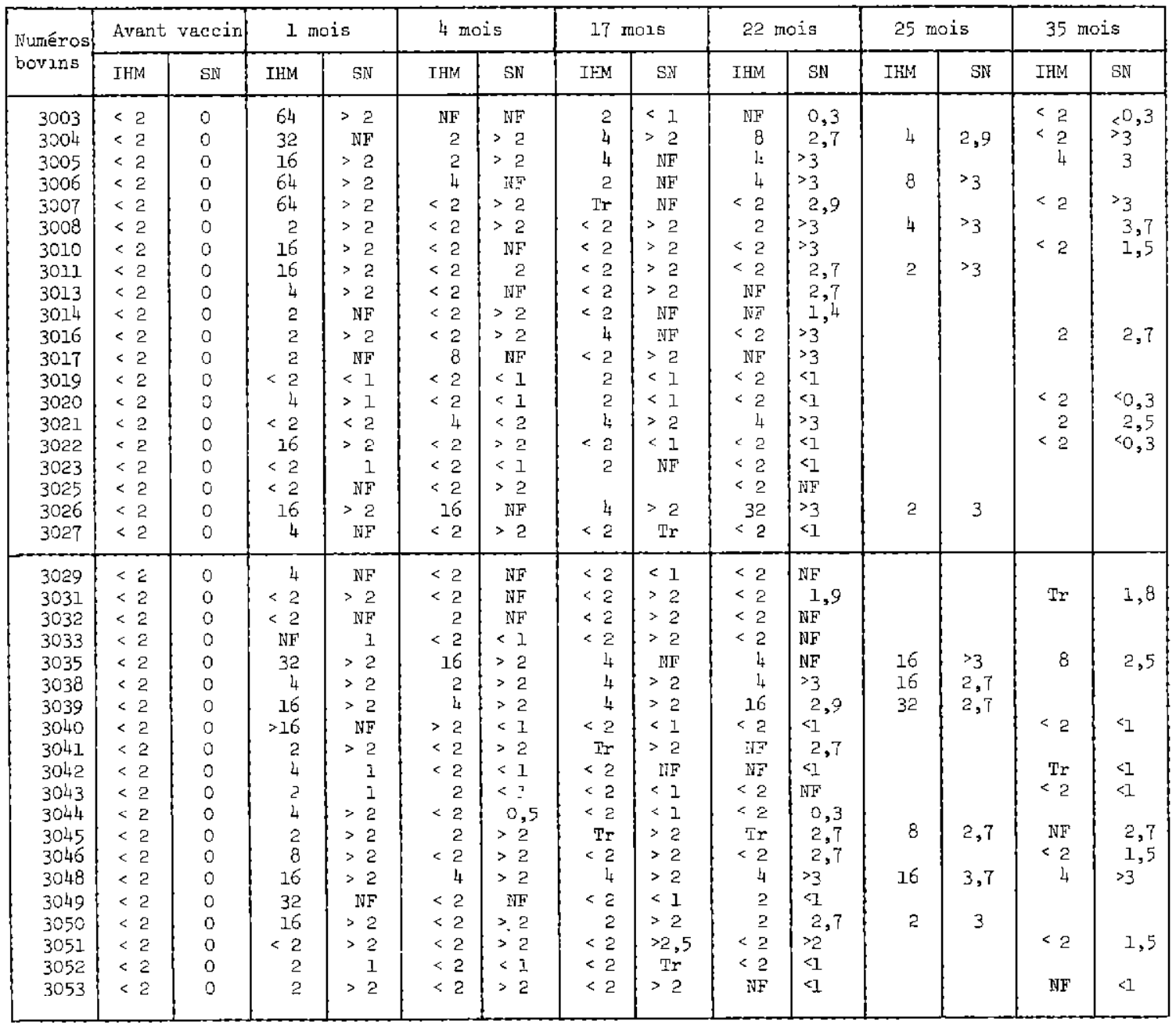

Ne figurent pas dans le tableau quelques animaux morts en cours d'expérience. IHM : test d'inhibıtion de l'hémagglutination morbllleuse. SN : test de séro-nedtralisation bovipestıque en cultures cellulaires. NF : test non exécuté. Les titres des anticorps Iil sont exprimés par l'inverse de la frection de la dilution inhibant I'hémagglutination morbilieuse; ceux des enticoros $5 N$ per le $\mathrm{TN}_{50}$ (titre neutralisant 50 p. 100 des sérums). 
et discutés dans une publication précédente (18); on $y$ avait montré la disparité des réponses fournies par la séro-neutralisation en cultures cellulaires ef l'inhibition de l'hémagglutination morbilleuse : celle-ci est négative chez $2 / 3$ des vaccinés à partir du 4 e mois après la vaccinatıon alors que 2 ans après, celle-là reste toujours sûrement positive pour 65 p. 100 d'entre eux.

Sans plus mentionner les résultats de l'inhibıtion de l'hémagglutination, l'évolution des anticorps neutralisants n'en reste pas moins digne d'intérêt. Un mois après la vaccination, tous les anımaux sauf deux, ont élaboré des anticorps ; le 3019 restera toujours négatif et le 3021 sera trouvé positif plus tard; dans l'ensemble, la vaccination a donc opéré la conversıon sérologique de 98 p. 100 des vaccinés.

II est surprenant de constater que quatre sujets sont, un mols après la vaccination, à la limite de la positivité ( $n^{\text {os }} 3023,3042,3043$ et 3052). Au quatrième mois, leur sérologie est redevenue négative ef l'est restée ensuite. Pour ces 4 bovıns, le vaccin en lui-même ne pouvant être mis en cause, on est conduit à invoquer des phénomènes immunologıques pressentıs mais non démontrés : réponse du type dose-effet pour des bovins ayant reçu une dose vaccinale incomplète, suite par exemple à une injection mal faite, ou réactivité immunologique amoindrie de genèse inconnue.

Treize animaux (nos 3003, 3020, 3022, 3023, $3027,3029,3040,3042,3043,3044,3052$ ef 3053) ont vu leurs titres en anticorps décroître et s'annuler en 17 à 22 mois. Au total, deux ans après la vaccination, 33 p. 100 des bovins vaccinés sont redevenus sérologiquement négatifs ou hébergent des anticorps d̀ un titre non protecteur. II ne paraît pas y avoir de différence attribuable à l'un ou à l'autre vaccın.

Sur les 26 animaux contrôlés entre la $2^{\mathrm{e}}$ et la 3 année, 7 ont des anticorps au-dessous du seuil protecteur. On notera que si entre la $2 \mathrm{e}$ ef la 3 année cucun animal n'est devenu négatif, on assiste pourtant au déclin des anticorps de 5 d'entre eux ( $n^{\text {os } 3010,3021,3035,3046}$ et 3051). On remarquera par contre la stabilité de certains sujets, tels les numéros 3004, 3007, 3008, 3048 ; i) n'en reste pas moins que certains animaux perdent relativement vite leurs anticorps.

On remarquera aussi un autre fait inattendu : le déclin ne paraît pas être régulier pour un individu donné comme cela devrait être de par les lois de l'immunologie générale ; il est possible toutefois qu'il s'agısse là d'erreurs expérimentales.

TABLEAIJ IY III

Comportement immuncloglque de bovins à scrclogie bovipestı gue positive Lors de contact av̈ec des maiades atteints de peste bovine.

\begin{tabular}{|c|c|c|c|c|c|c|c|}
\hline \multirow{2}{*}{\multicolumn{2}{|c|}{ Juméro des bovins }} & \multicolumn{2}{|c|}{$\bar{J}$} & \multicolumn{2}{|c|}{$J+-I$} & \multicolumn{2}{|c|}{$=+16$} \\
\hline & & I H & $S \mathbb{N}$ & I H M & $\mathrm{SH}$ & $\mathrm{IH} \mathrm{H}$ & $5 \mathrm{r}$ \\
\hline \multirow{8}{*}{ 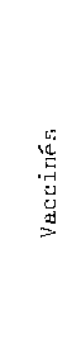 } & 3006 & 8 & $>3$ & $I \epsilon$ & $\Xi$ & 34 & 3 \\
\hline & 3008 & 4 & 3 & 2 & 3 & 4 & 3 \\
\hline & 3011 & 2 & 3 & $\varepsilon$ & 3 & 8 & 3 \\
\hline & 3026 & 2 & 3 & 32 & 3 & 128 & 3 \\
\hline & 3038 & 16 & 2,7 & 32 & 3 & 16 & 3 \\
\hline & 3039 & 32 & 2,7 & 32 & 3 & 32 & 3 \\
\hline & 3045 & 8 & 2,7 & 8 & 3 & c & 3 \\
\hline & 3050 & 2 & 3 & 2 & 3 & 8 & 3 \\
\hline 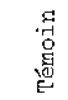 & 2980 & $<2$ & 0 & $<2$ & 0 & 8 & 0,7 \\
\hline
\end{tabular}

Le jour J désigne le jour de la mise en contact (durée 3 iours) avec deux oovins pestiques. Le bovin témoin est introàuit हे $\mathrm{J}+3$. 
2. Epreuve bovipestique de bovins sérologiquement positifs réalisée 2 ans après la vaccination.

Les animaux avaient été choisis parmi ceux possédant une sérologie morbilleuse positive : il en était de même, bien sûr de la sérologie pestique.

Lo récapitulation de l'épreuve est donnée dans le tableau no 3 .

Sur les 8 bovins contaminés, trois $(3038,3039$, 3050) présentent un peu de larmoiement 9 jours après la mise en contact ; le lendemain rien n'y paraît plus. Le bovin réceptif $\left(n^{\circ} 2980\right)$ débute la peste 10 jours après son introduction auprès des contaminés ; Il meurt 6 jours plus tard.

Le virus pestique est isolé à deux reprises des prélèvements nasaux des bovins 3006 et 3026 . Il est intéressant de constater qu'aucune activité inhibitrice du mucus nasal envers le virus de cultures cellulaires n'est détectée dans les échantillons de mucus, hormis pour le 3006 le 6 e jour après le contact ; le virus n'est plus retrouvé dans les prélèvements à partır de cette date.

Les anticorps sérıques neutralisants se maıntiennent à un titre à peu près stable, aux erreurs expérimentales près. Les anticorps inhıbant I'hémagglutination morbilleuse des nos 3006 et 3026 ont accusé une augmentation de titre.

II est aisé de conclure que sur les 8 bovins vaccinés contaminés, 2 au moins se sont infectés de peste de façon occulte, qu'ils ont excrété ensuite le virus qui a contaminé le zébu témoin. La présence d'anticorps sériques n'est done pas la garantie d'une immunité virologique mais celle d'une immunité clinique. Dans des conditions de transmissions du contage pestıque simulant au mieux les conditions naturelles, il est clairement démontré que des bovins correctement vaccınés contre la peste et hébergeant des anticorps antipestiques peuvent être épisodiquement des colporteurs méconnus du virus. II n'y a pas lieu d'en faire une généralısation mais le fait acquis pour 2 bovins sur 8 a valeur de certitude.

Si le virus a été réısolé à partir du mucus nasal, rien ne permet de penser par contre qu'il $y$ ait pu avoir virémie; bien qu'elle n'alt pas été recherchée, ce que l'on sait du comportement in vivo des myxovirus et du virus bovipestique en particulier laisse augurer qu'elle n'a dô exister chez aucun animal contaminé étant donné les hauts titres en anticorps neutralisants. Par contre, la présence du virus dans le mucus nasal est, quant à elle, parfaitement plausible par sulte de l'absence d'activité inhıbitrıce du mucus ; sans pouvoir en préciser l'origine, il est concevable que le virus de contamination se réplique dans les voies aérifères supérieures, soit dans l'épıthélium, soit plus volontiers, dans les follicules lymphatiques superficiels de cet épithélium (seule une culture d'organe, à réalıser, tranchera la question), éventuellement dans les cellules conjonctivales. Incidemment, on constatera le rôle que l'on est conduit à Imputer pour les voies aériennes supérieures chez des bovins immuns; pressenti par des observations épizootiologiques (21), expérimentalement démontré par dépôt local de virus (12), ce rôle est clairement prouvé dans la présente expérience. L'incidence de cette constatation sur la prophylaxie sanitaire sera montrée plus loin.

Un autre point remarquable est l'absence d'activité inhibıtrice du virus pestique dans le mucus nasal des vaccinés. Il s'agit là d'une question extrêmement importante qui a donné lieu à un thème de recherches exposé dans une publication à venir.

On peut se demander pourquoi deux bovins seulement ont été trouvés infectés. Aucune réponse certaine ne peut être apportée : ce peut tout aussi bien être dû à des fautes de techniques dans le réisolement qu'à une véritable noninfection, soit par suite de facteurs ımmunitares locaux méconnus, solt par suite d'une moindre exposition au contage. Le fait d'importance, positif, n'en reste pas moins que deux bovins immuns ont véhiculé le virus dans les conditions de l'expérience

3. Epreuve bovipestique de bovins d sérologie variable réalisée 3 ans après la vaccination.

Au moment de l'épreuve par contact, la sérologie pestique des animaux vaccinés était variable : 10 sur 16 possédaient des anticorps

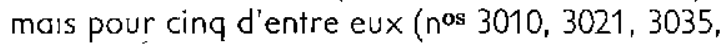
3046 ef 3051) ils amorçalent déjà leur déclın ; les 6 autres, ou n'en possédaient plus ou en possédalent à un taux insignifiant.

Le tableau $n^{\circ} 4$ retrace leur évolution sérologique et clınique.

On constate d̀ l'examen que 7 animaux (n ${ }^{\text {os }} 3003,3020,3022,3040,3042,3043$ et 5026) 
TABJ.TAU $\mathbb{H}^{\circ}$ IV

Comportement clinique ct immunologique de bovins vaccinés depuls 3 ans contre la peste lors de contact avec des malades atteint:s de peste bovine.

\begin{tabular}{|c|c|c|c|c|c|c|c|c|c|c|c|c|c|c|c|c|c|}
\hline \multirow{3}{*}{\multicolumn{2}{|c|}{ Numéros }} & \multicolumn{10}{|c|}{ Evolution des antıcorps sériques } & \multirow{2}{*}{\multicolumn{3}{|c|}{ Isolement virus }} & \multirow{2}{*}{\multicolumn{2}{|c|}{$A c J+I I$}} & \multirow{3}{*}{ Observations } \\
\hline & & \multicolumn{2}{|c|}{$\begin{array}{l}\text { Avant } \\
\text { vaccin }\end{array}$} & \multicolumn{2}{|c|}{1 mois } & \multicolumn{2}{|c|}{4 mois } & \multicolumn{2}{|c|}{$\begin{array}{c}22-25 e ̀ ~ \\
\text { mois }\end{array}$} & \multicolumn{2}{|c|}{$\begin{array}{r}35 e ̀ ~ \\
\text { mois }\end{array}$} & & & & & & \\
\hline & & IHM & SN & IHM & Siv & IHM & SII & IHM & SIN & IHM & $\mathrm{SN}$ & $\mathrm{J}+5$ & $\mathrm{~J}+8$ & $\mathrm{~J}+10$ & IHM & SN & \\
\hline & 3003 & $<2$ & 0 & 64 & $>2$ & & & $\mathrm{NF}$ & $<0,3$ & $<2$ & $<0, ?$ & - & + & & & 0,3 & Peste, mort $\mathrm{J}+13$ \\
\hline & 3005 & $<2$ & 0 & 16 & $>2$ & 2 & $=2$ & 4 & 2,9 & $<2$ & $>3$ & - & - & - & 4 & $>3$ & Normal \\
\hline & 3007 & $<2$ & 0 & 64 & $>2$ & $<2$ & $>2$ & $<2$ & 2,9 & $<2$ & $>3$ & - & 5 & - & & $>3$ & Normal \\
\hline & 3010 & $<2$ & 0 & 16 & $>2$ & 2 & $\mathbb{N E}$ & $<2$ & 23 & -2 & 1,5 & - & - & - & 8 & $>3$ & Diarrhée \\
\hline & 3016 & $<2$ & 0 & 2 & $>2$ & $<2$ & $>2$ & $<2$ & $>3$ & $<2$ & 2,7 & - & - & - & $<2$ & 2,7 & Normal \\
\hline & 3020 & $<2$ & 0 & 4 & $>1$ & $<2$ & $<1$ & $<2$ & $<1$ & $<2$ & $<0,3$ & - & - & - & $<2$ & $<0,3$ & Peste, mort $J+13$ \\
\hline (2) & 3021 & $<2$ & 0 & $<2$ & $<2$ & 4 & $>2$ & 4 & $>3$ & 2 & 2,5 & - & - & - & 4 & 1,8 & Normal \\
\hline a & 3022 & $<2$ & 0 & 16 & $>2$ & 2 & $>2$ & $<2$ & $<1$ & $<2$ & $<0,3$ & - & $\Xi$ & - & $<2$ & $<0,3$ & Peste, mort $\mathrm{J}+13$ \\
\hline .40 & 3035 & $<2$ & 0 & 32 & $>2$ & 16 & $>2$ & 16 & $>3$ & 8 & 2,5 & - & - & - & & 1,7 & Normal \\
\hline 0 & 3040 & $<2$ & 0 & $>1.6$ & $\mathbb{N F}$ & $<2$ & $<I$ & $<2$ & $<1$ & $<2$ & $<1$ & - & - & - & $<2$ & 0,9 & Peste, mort $\mathrm{J}+14$ \\
\hline$p$ & 3042 & $<2$ & 0 & 4 & 1 & $<$ & $<1$ & $\mathrm{INF}$ & $\Leftrightarrow 1$ & $\mathrm{Tr}$ & $<1$ & s & + & - & $<2$ & 1,8 & Peste, guêrit \\
\hline & 3043 & $<2$ & 0 & 2 & 1. & 2 & $<1$ & $\mathrm{NF}$ & $<2$. & $<2$ & 0,3 & - & + & - & & 0,9 & Peste, mort J+2l \\
\hline & $301+6$ & $<2$ & 0 & 8 & $>2$ & $<2$ & $>2$ & $<2$ & 2,7 & $<?$ & 1,5 & - & & & 16 & $=3$ & Normal \\
\hline & 3048 & $<2$ & 0 & 16 & $>2$ & 4 & $>2$ & 4 & $>3$ & 4 & $>3$ & - & - & - & 4 & $>3$ & Normal \\
\hline & 3051 & $<2$ & 0 & $<2$ & $>2$ & $<2$ & $>2$ & $<2$ & 2,5 & $<2$ & 1,5 & + & - & - & $\therefore 2$ & 1,5 & Larmoiement \\
\hline & $\begin{array}{l}5026 \\
3053\end{array}$ & $\div 2$ & 0 & 2 & $>2$ & $<2$ & $>2$ & $<2$ & $>2$ & $\mathrm{NF}$ & $<1$ & & + & - & $\operatorname{Tr}$ & 0,6 & Peste guérit \\
\hline & 3057 & $<2$ & 0 & $<2$ & 0 & $<2$ & 0 & $<2$ & 0 & $<2$ & 0 & & + & - & $<2$ & 0,9 & Peste guérit \\
\hline 氙 & 5023 & & & . & & & & & & $\div 2$ & 0 & & & - & $<2$ & 0,3 & Feste, mort $J+21$ \\
\hline 酎 & 5024 & & & & & & & & & $<2$ & 0 & & + & - & $<2$ & 0,3 & Peste, mort $\mathrm{J}+16$ \\
\hline & 5025 & & & & & & & & & $<2$ & 0 & & + & - & $<2$ & $<0,3$ & Peste, mort $\mathrm{J}+16$ \\
\hline
\end{tabular}

J désigne lc jour de la mise en contact des Lèmoins avec les bovins éprouvés. 
ont contracté une peste bovine clinique; ce sont ceux-là mêmes qui n'ont que peu ou pas d'anticorps. Cing d'entre eux meurent; deux guérissent. Deux autres bovins (3010 ef 3052) ne présentent que des symptômes frustes (un peu de larmoiement et de diarrhée) ; on remarquera que dans le groupe hébergeant des anticorps, ils sont de ceux qui ont le plus bas titre.

Les quatres témoins introduits contractent tous quatre la pesie, ce qui n'a rien de surprenant.

Le virus pestique est isolé à plusieurs reprises du mucus nasal y compris de celui du no 3051 qui n'a eu qu'un bref accès de larmoiement.

Onze jours après la mise en contact, la sérologie n'a que peu varié, aux erreurs expérimentales près, sauf pour le 3042 qui a contracté la peste et a guéri, pour le 3010 qui n'a présenté qu'un trouble passager ainsi que pour le 3046 dont le comportement clinique a pourtant été normal.

La recherche de l'activité inhibitrice du mucus nasal n'a pu être effectuée par suite d'une erreur de manipulation.

Moins démonstrative que l'épreuve précédente, la présente mise en contact virulent montre pourtant clairement que 3 ans après la vaccination (correctement effectuée car suivie de conversion sérologique) de bovins maintenus par la suite d̀ l'abri de contacts pestiques, 44 p. 100 d'entre eux contractent la peste après avoir vu décliner leurs anticorps.

\section{DISCUSSION}

Les résultats de l'expérience qui vient d'être rapportée sont révélateurs. A l'encontre de ce que I'on peut attendre pour le vaccin caprinisé, les vaccins antibovipestiques de cultures cellulaires correctement préparés, contrôlés et inoculés aux doses recommandées ne semblent conduire qu'à une immunité de quelques années, avec le tiers des animaux ayant perdu leurs anticorps en l'espace de 2 ans. On se retrouve dans les limites connues pour les autres virus-vaccins antipestiques, le caprinisé excepié.

En dehors des observations de PLOWRIGHT ef TAYLOR au Kénya (15), il ne paraît pas exister d'essais réalisés dans des conditions identiques: la comparaison des résultałs de PLOWRIGHT et des nôtres devient alors fructueuse.

Concernant l'évolution des anticorps post-vaccinaux, on constate que l'un des groupes de bovins («grade cattle») vaccinés par PLOWRIGHT se comporte comme ceux de la présente expérience : aux mêmes époques, plus de la moitié d'entre eux sont en dessous du titre protecteur, avec amorce du déclin après la première année. Le comportement de leurs deux groupes de zébus Borans et Ankole diffère par contre totalement de celui de nos zébus Bororos ; leurs antıcorps se sont montrés être stables pendant 4 ans. II n'y a pas lieu d'épiloguer, mais d'accepter les faits. Tout comme à Bouar, les zébus Est-Africains étaient soustraits à des réinfections par leur entretien en station dans un milieu sain $i$ on ne peut penser pour eux à un éventuel rappel par infection occulte. Il est autant difficile d'invoquer une résistance naturelle des zébus Bororos à la peste ayant pu modifier l'immunogenèse ; la maladie est inconnue en R. C. A. et l'expérience est là pour prouver leur réceptivité, ne serait-ce que par l'importante mortalité qui suit l'infection expérimentale.

Ces conclusions doivent rendre prudent le planificateur de campagne de vaccination (9). Dans les conditions de l'Afrique centrale, il ne paraît pas que l'on puisse tabler sur une immunité de plus de 18 mois pour 80 p. 100 des bovins vaccinés avec les vaccins de cultures cellulaires, proportion minimale d'animaux immuns dont on affirme qu'elle garantit le bon état sanitaire au regard de la peste (20). Sage paraît alors être le conseıl donné de continuer à vaccıner ef revacciner tout le cheptel, si possible annuellement ou au moins tous les deux ans, même après la fin de la campagne interafricaine et tant qu'existeront des foyers résiduels de peste bovine.

$\mathrm{Cecl}$ est dit en appréciant parfaitement les Implications financières que recèle en elle une telle proposition. II paraît difficile, dans l'état actuel de nos connaissances, de pouvoir $y$ échapper. La simple observation des faits dans la zone couverte par la phase I de la campagne antipestique interafricaine est d'alleurs là pour étayer cette opinion : si des foyers résiduels de peste sont bien plus nombreux chez les veaux non vaccinés, on en connaît pourtant déjà 
quelques authentiques chez des adultes vaccinés. II est'vrai que n'a pas encore été appréciée l'éventuelle action anamnestique sur les anticorps du colportage du virus à partir de ces foyers.

II paraît vraisemblable que ce rappel anamnestique existe au regard des résultats exposés dans le tableau 4 , où 3 bovins sur 10 restés en bonne santé voient se produire un rappel de leurs anticorps. Il se peut donc que dans la nature la situation solt différente de celle de la présente expérience, mais il est tout de même ıllogıque de tabler sur l'existence éventuelle de tels foyers, pour que s'effectuent des rappels et que se maintiennent des titres valables d'anticorps chez les vaccınés.

L'un des autres enseignements de cette expérience est d'avoir montré la possibilité d'infection occulte et de dissémination du contage par des bovins vaccinés et, partant, son influence sur les anticorps. Les conséquences en sont nombreuses.

Ainsi, par exemple, se trouve explıquée la pérennité de la peste dans certaınes régions d'enzootie. Les jeunes bovins non vaccinés avalent été accusés d'être les réservoirs du virus pestique par les foyers qu'ils créaient. On peut se demander, au contralre, s'ils ne sont pas les révélateurs, puis les victimes, d'une infection colportée par des adultes immuns dans leurs voles nasales supérieures. Ce sont ces adultes, en effet, qui sont l'objet de transactions commerciales ou rituelles et non les veaux. Ainsi s'explıque l'éclosion de foyers d̀ distance sans qu'ily ait forcément transfert de malades. Dans cet ordre d'ıdée, on peut se demander si l'apparition de la peste bovine en pays vierge d'infection n'a pas d'autre origine $(21,22)$, ef l'on mesurera, si besoin en était encore, le danger que présente l'importation d'artiodactyles même vaccınés. Ainsi peut s'expliquer également l'entretien de l'infection pestique dans une communauté anımale close, telle celle des gnous du Tanganyika qu'a étudiée PLOWRIGHT (10).

On conçoıt aussı, et bien qu'ayant allure d'aphorisme, cela est trop souvent oublié, la vanité des espoirs d'éradication de la peste bovine lorsque ne sont pas associées à la vaccination les mesures sanitaires classiques de séquestration et d'abattage. Ce sont les seuls moyens d'éviter le colportage occulte du virus par des bovins immuns. La vaccination ne paraît être là que pour protéger cliniquement les animaux ; elle n'assure pas la disparition de l'infection larsqu'existent des recontaminations ; paradoxalement, on pourrait même l'accuser de l'entretenir à bas bruit. L'immunité antipestique paraît être ainsi à deux facettes : individuelle et collective : la vaccination n'assure que la première, la prophylaxie sanıtaire doit maintenir la seconde. Là où l'abattage a été pratiqué concuremment d̀ la vaccination, la peste a disparu ; là où ।l est différé, elle subsiste.

Une autre conséquence est l'absence d'assurance de contamination pestique des viandes de boucherie que donne la présence d'antıcorps. On aurait pu imaginer que des bovins de boucherie destinés à l'exportation solent testés avant l'abattage en recherchant, par exemple, les anticorps inhibant l'hémagglutination, épreuve simple et rapide à mettre en ceuvre. II est claır, d'après le tableau 3, que ce test n'offre aucune garantie.

On notera qu'en ce qui concerne l'épreuve virulente, nos résultats divergent d'avec ceux de PLOWRIGHT ef TAYLOR (15), mais que le protocole d'exécution est parfaitement différent : les expérimentateurs de I'E. A. V. R. O. ont inoculé leurs bovins tandis que les nôtres ont été mis en contact avec des malades. On peut augurer, au vu du titre de leurs anticorps que les nôtres se seralent comportés en bovins parfaitement immuns sans contamination de leurs congénères réceptıfs s'ils avalent été inoculés par voie souscutanée. On remarquera pourtant que l'un des animaux de PLOWRIGHT ef TAYLOR, sans paraître lui-même malade, a, 28 mois après la vaccination, contamıné le bovin réceptif placé à son contact après l'épreuve virulente souscutanée.

Ainsi qu'on l'a souligné à plusieurs reprises, la découverte de cette expérience est la réceptivité des voies aériennes supérieures à l'ınfection pestique chez les bovins immuns. Cette constatation a été l'objet d'une fructueuse ligne de recherches dont les résultats seront exposés dans une publication à venir. 


\section{SUMMARY}

Clinical and immunological behaviour during an exposure to rinderpest of rinderpest cell-culture vaccinated cattle.

It is stated that in the conditions of the trial (2 year old zebu cattle, vaccinated with the recommanded dose with two kinds of live cell culture vaccines, then maintained in a rinderpest-free area) 33 p. 100 of vaccinated cattle loose their rinderpest antibodies within 2 years.

Such vaccinated (serologically positive) cattle do not show clinical rinderpest when challenged by contact exposure 25 months after vaccination but harbour virulent virus in their nasal mucus and are able to contaminate an in-confact receptive animal.

It is thought that in some animals the rinderpest Immunity induced by cell-culture vaccines is not life-long when cattle are not exposed to natural contamınation and that some vaccinated catile can act as unnoticed agents in rinderpest tranșmissıon.

\section{RESUMEN}

Comportamiento clinico e inmunológico durante la contaminación bovipesfica de bovinos vacunados desde algunos años contra la peste boyina con vacunas de culfiyos celulares

En las condiciones de la experiencia (cebues de 2 años, vacunados contra la peste bovina en dosis recomendados en la práctica con dos vacunas diferentes de cultivos celulares, luego mantenidos a cubierto de una contaminación pestica), se comproba que 33 p. 100 de los bovinos vacunados han perdido sus anticuerpos sericos antipesticos post-vacunıcos a los 2 años.

- Tales bovinos vacunados, con serologia antipestica positiva, sometidos 25 meses despues de la vacunación a una prueba virulenta por contacto no presentan peste clinica pero pueden vehıculızar el virus en su mucus nasal y contamınar un bovino receptivo colocado en su contacto. Se hace la prueba virulenta el tercero año : en 7 bovinos de 17 ocurre la peste, en 3 se encuentra un aumento de sus anticuerpos.

Esto hace pensar que cuando los bovinos vacunados no estan sometidos a otras contaminaciones, la inmunidad antipestica causada por los vacunas de cultivos celulares no permanece durante la vida entera del bovino vacunado $y_{1}$ por otra parle, que bovinos inmunes pueden ser vehículos desconocidos del contagio pestico.

\section{BIBLIOGRAPHIE}

1. ANONYME. - Recherches sur la persistance $d u$ virus pestique dans les viandes réfrigérées provenant de bovins afteints de peste bovine et sur la possibilité de propagation de celle-ci par les viandes d'animaux exportées des régions infestées. Rapport final. Publication IEMVT, Alfort, 1965, 122 pages, ronéoté.

2. ANONYME. - Requirements for Rinderpest vaccines (live; for veterinary use). Document OMS non publié.

3. BÖGEL (K.), ENDERS-RUCKLE (G.) et
PROVOST (A.). - Une réaction sérologique rapide de mesure des anticorps antibovipestiques. C. R. Acad. Sci. (Paris), 1964, 259 : 482-484.

4. BOURDIN ( $\left.P_{1}\right)$. - Durée de l'élimination du virus pestique chez des bovins immunisés avec un vaccin inactivé. Rev. Elev. Méd. Vét. Pays trop., 1968, $21: 141-144$.

5. BROTHERSTON (J. G.). - Rinderpest : some notes on control by modified virus vaccines II, Vet. Rev. Ann., 1957, 2 : 4546. 
6. BROWN (R. D.). - Duration of rinderpest immunity in cattle following vaccination with caprinized rinderpest virus. Bull. epiz. Dis. Afr., 1965, $13: 311-315$.

7. DE BOER (C. J.) et BARBER (T. L.). Segregation of an virulent variant of rinderpest virus by the terminal dilution technique in tissue culture. J. Imm., 1964, 92 : 902-907.

8. HUDSON (J. R.) et DANKS (W. C. B.). Avianised virus. Rpt. Vet. Dpt. Kenya, Nairobi, The Government Printer, 1947.

9. LÉPISSIER (H.) et MACFARLANE (l.). Techniques de vaccinations massives en vue de contrôler l'expansion de la peste bovine (campagne conjoinfe contre la peste bovine PC15). Bull. O. 1. E., 1967, $68: 665-689$.

10. PLOWRIGHT (W.). - The application of monolayers tissue culture techniques in rinderpest research. II. The use of attenuated culture virus as a vaccine for cattle. Bull. O. I. E., 1962, $57: 253-276$.

11. PLOWRIGHT (W.). - The role of game animals in the epizootiology of rinderpest and malignant catarrhal fever in East Africa. Bull. epiz. Dis. Afr., 1963, 11 : 149-162.

12. PLOWRIGHT (W.). - Studies on the pathogenesis of rinderpest in experimental cattle. II. Proliferation of the virus in different tissues following intranasal infection. J. Hyg., $1964,62: 257-281$.

13. PLOWRIGHT (W.) et FERRIS (R. D.). Studies with rinderpest virus in tissue cultures. I. Growth and cytopathogenicity. J. comp. Poth., 1959, $69: 162-172$.

14. PLOWRIGHT (W.) et FERRIS (R. D.). Studies with rinderpest virus in tissue cultures. III. The stability of the cultured virus and its use in virus neutralization tests. Arch. ges. Virusf., 1961, 11 : 516-533.
15. PLOWRIGHT (W.) et TAYLOR (W. P.). Long term of the immunity in East African cattle following inoculation with rinderpest culture vaccine. Res. Vet. Sci., 1967, 8 : 118128.

16. PROVOST (A.), BORREDON (C.) et QUEVAL (R.). - Recherches immunologiques sur la péripneumonie. XII. Un vaccin vivant mixte antibovipestique-antipéripneumonique inoculé en un seul temps. Bull. O. 1. E., 1969, 71.

17. PROVOST (A.), MAURICE (Y.) et BORREDON (C.). - Note sur la peste bovine expérimentale du dromadaire. Rev. Elev. Méd. Vét. Pays trop., 1968, 21 : 293-296.

18. PROVOST (A.), MAURICE (Y.) et BORREDON (C.). - Possibilités ef limites de la réaction d'inhibition de l'hémagglutination morbilleuse dans la sérologie de la peste bovine. II. Disparité des résultats fournis par cette réaction ef celle de séro-neutralisation du virus bovipestique. Rev. Elev. Méd. Vét. Pays trop., 1969, 22 : 9-15.

19. PROVOST (A.), VILLEMOT (J. M.) et QUEVAL (R.). - Emploi du vaccin avianisé souche BA contre la peste bovine en Afrique centrale. Rev. Elev. Méd. Vét. Pays trop., 1961, $14: 375-383$.

20. ROWE ( $L$. W. . . - A screening survey for rinderpest neutralising antibodies in cattle in Northern Nigeria. Bull. epiz. Dis. Afr., 1966, $14: 49-52$.

21. SCOTT (G. R.). - The risk associated with the importation of meat from countries where rinderpest control measures are still required. Bull. epiz. Dis. Afr., 1957, 5 : 11-13.

22. $\operatorname{SCOTT}$ (G. R.). - Rinderpest. Adv. Vet. Sci., $1964,9: 113-224$. 